\title{
Towards low-friction and wear-resistant plasma sintering dies via plasma surface co-alloying CM247 nickel alloy with VIAg and $N$
}

\author{
Zhenxue Zhang ${ }^{1, a}$, Xiaoying Li ${ }^{1}$, Hanshan Dong ${ }^{1}$, Eluxka Almandoz Sánchez ${ }^{2}$, Gonzalo García \\ Fuentes $^{2}$, and Yi Qin ${ }^{3}$ \\ ${ }^{1}$ The University of Birmingham, Birmingham B15 2TT, UK \\ ${ }^{2}$ AIN, Cordovilla (Navarra) 31191, Spain \\ ${ }^{3}$ The University of Strathclyde, Glasgow G1 1XJ, UK
}

\begin{abstract}
Nickel based superalloys have good oxidation and creep resistance and hence they can function under high mechanical stress and high temperatures. However, their undesirable tribological behaviour is the major technical barrier to the challenging high-temperature, lubricant-free plasma sintering tool application. In this study, nickel based CM247 superalloy surfaces were co-alloyed using innovative active screen plasma technology with both interstitial element (e.g. N) and substitutional alloying elements (e.g. $\mathrm{V}$ and $\mathrm{Ag}$ ) to provide a synergy effect to enhance its tribological properties. The tribological behaviour of the plasma co-alloyed CM247 superalloy surfaces were fully evaluated using reciprocal and pin-on-disc tribometers at temperatures from room temperature to $600^{\circ} \mathrm{C}$. The experimental results demonstrate that the co-alloyed surface with $\mathrm{N}, \mathrm{Ag}$ and $\mathrm{V}$ can effectively lower the friction coefficient, which is expected to help demoulding during lubricant-free plasma sintering.
\end{abstract}

\section{Introduction}

As an advanced field-activated and pressure-assisted sintering process, plasma sintering or electric field-activated sintering technology (FAST) enables binder-free, rapid sintering of high-performance components with nano-structured micro-powders. This FAST process is particularly suitable for massproduction of miniature or micro-parts (i.e. Micro-FAST) due to its rapid heating nature. However, the small tools not only withstand high temperature but also experience cyclic high heating /cooling rates. When the size of the tools and components is scaled down to mm-scale, soldering due to severe adhesion between the mould and the working material would occur and thus demoulding becomes a major challenge.

Graphite is usually the most widely used material for FAST tools (die/punch) because of its high electric conductivity, high temperature stability and oxidation resistance [2, 3]. It does, however, have a low load bearing capacity, with a maximum pressure capability of 80-150 MPa; graphite dies could

\footnotetext{
${ }^{\text {a }}$ Corresponding author: zhzhxue@yahoo.com
}

This is an Open Access article distributed under the terms of the Creative Commons Attribution License 4.0, which permits unrestricted use, distribution, and reproduction in any medium, provided the original work is properly cited. 
Table 1. Elements and their composition in CM247LC (wt \%).

\begin{tabular}{cccccccccccc}
\hline $\mathrm{C}$ & $\mathrm{Cr}$ & $\mathrm{Co}$ & $W$ & $\mathrm{Mo}$ & $\mathrm{Ta}$ & $\mathrm{Al}$ & $\mathrm{Ti}$ & $\mathrm{Hf}$ & $\mathrm{B}$ & $\mathrm{Zr}$ & $\mathrm{Ni}$ \\
\hline 0.15 & 8.4 & 10 & 10 & 0.7 & 3.0 & 5.5 & 1.0 & 1.5 & 0.015 & 0.015 & Bal. \\
\hline
\end{tabular}

also cause carbon contamination for functional components. When sintering high-strength materials at high-temperature, dies must be made from superalloys, refractory metal alloys or even ceramics [4]. Due to its superior high temperature strength, high oxidation resistance and good thermal fatigue resistance, Ni-based CM247LC superalloy could be a suitable candidate material for Micro-FAST tools used under high-pressure $(>140 \mathrm{MPa})$ and at high-temperature $\left(<1000^{\circ} \mathrm{C}\right)[5]$.

Although the wear properties of hot forming tools can be effectively improved by a variety of surface engineering processes [6], high-friction is still a major technical concern especially for hot forming small parts. Some refractory metal nitride coatings, such as VN, have been studied recently due to the possibility of forming low-friction Magnéli phase at high temperature, e.g. $\mathrm{V}_{2} \mathrm{O}_{5}$. Noble metals such as silver can be added into oxides and nitrides to form composites thus providing extra solid lubrication at a wide range of temperatures up to $1000^{\circ} \mathrm{C}[7,8]$.

However, little work has been devoted to improve the tribological properties of Ni-based superalloys for hot forming tools. In this research, a novel surface engineering technology based on active-screen surface co-alloying has been developed to improve the tribological properties (high wear resistance and low-friction) of CM247LC alloy potentially for high-performance and long-life Micro-FAST dies.

\section{Experimental}

Nickel-based CM247LC superalloy was manufactured by hot isostatic pressing under $150 \mathrm{MPa}$ at $1260{ }^{\circ} \mathrm{C}$ followed by a solution treatment for improved tensile and high cycle fatigue strength. This is a modified superalloy based on Mar-M247 and its composition is listed in Table 1.

Blocks of $20 \times 15 \times 5 \mathrm{~mm}$ were sectioned and wet ground individually with $\mathrm{SiC}$ sand paper down to 1200 grit, followed by progressive polishing with 9,6 and $1 \mu \mathrm{m}$ diamond paste. After ultrasonic cleaning in acetone bath, the blocks were dried with hot air.

Plasma surface co-alloying of the samples was carried in a modified $60 \mathrm{~kW}$ Klöchner DC plasma furnace at a pressure of 4 mbar. A stainless steel cage with silver and/or vanadium addition was used as an active screen in the plasma treatment. A DC voltage from 300 to $1000 \mathrm{~V}$ was applied between the active screen (the cathode) and the wall of the furnace (the anode) during the plasma co-alloying process. Plasma was formed on the metal mesh screen and samples were at a floating potential without plasma coverage during the treatment. The active screen plasma (ASP) co-alloying treatments were carried out at $450{ }^{\circ} \mathrm{C}$ for 25 hours under a pressure of 4 mbar in a gas mixture of $25 \%$ nitrogen and $75 \%$ hydrogen. During the treatment, the samples surfaces were alloyed simultaneously with both interstitial element (i.e. $\mathrm{N}$ through nitriding) and substitutional alloying elements (i.e. $\mathrm{V}$ and $\mathrm{Ag}$ ). The diffusion of $\mathrm{N}$ could form a relatively thick hardened case by solid solution hardening and precipitation hardening; the coalloyed $\mathrm{V}$ and $\mathrm{Ag}$ would reduce friction at elevated temperature mainly due to the solid lubricating effect of in-situ formed $\mathrm{V}_{2} \mathrm{O}_{5}$ and doped $\mathrm{Ag}$.

The phase constitution of the plasma co-alloyed layers was identified by X-ray diffraction (Philips X'pert X-Ray diffractometer) using a Cu- $\mathrm{K}_{\alpha}$ radiation $(\lambda=0.154 \mathrm{~nm})$. The surface morphologies of the plasma treated specimens were observed under scanning electron microscopies (SEM). Surface microhardness was measured using a Vickers microhardness tester (Mitutoyo MVK-H1) under a load of 25 gf. Specimens were electrically etched in a $10 \% \mathrm{H}_{3} \mathrm{PO}_{4}$ solution before cross-sectional layer structure observation by SEM. An EDX facility adapted to the SEM was used for the local composition analysis during the SEM observation.

A TE79 multi-axis tribometer was used to assess the friction and wear of the surface engineered and untreated material for comparison. A $8 \mathrm{~mm}$ in diameter alumina ball was used as the counterpart under 


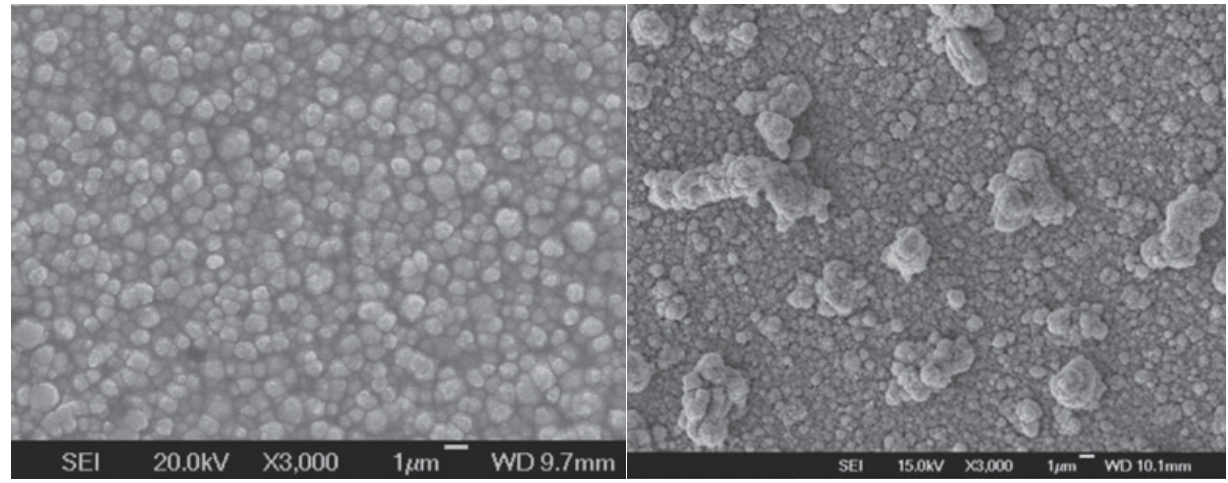

(a)

(b)

Figure 1. Surface morphology of samples treated at $450{ }^{\circ} \mathrm{C}$ for 25 hours in an atmosphere of $25 \% \mathrm{~N}_{2} / 75 \% \mathrm{H}_{2}$ : (a) plasma nitrided and, (b) active screen co-alloyed surface with $\mathrm{N}$ and $\mathrm{V} / \mathrm{Ag}$.

Table 2. Surface roughness, micro-hardness and wear area of CM247LC samples.

\begin{tabular}{ccccc}
\hline Treatment & Sample Code & $R a(\mu m)$ & $H V_{0.025}$ & Wear Area $\left(\mu m^{2}\right)$ \\
\hline Untreated & Untreated & 0.0317 & 359 & 126 \\
N Alloying (nitriding) & PN_25N & 0.0997 & 730 & 62 \\
N/V co-alloying & V_25N & 0.0462 & 454 & 42 \\
N/V/Ag co-alloying & V/Ag_25N & 0.0982 & 381 & 480 \\
\hline
\end{tabular}

a load of $2 \mathrm{~N}$ during tribo-test at room temperature. The reciprocating sliding distance was set to $5 \mathrm{~mm}$, the sliding speed was $10 \mathrm{~mm} / \mathrm{s}$, and the coefficient of friction was recorded for 1000 cycles. Pin-on-disc friction test under a load of $2 \mathrm{~N}$ with an $\mathrm{Al}_{2} \mathrm{O}_{3}$ ball of $6 \mathrm{~mm}$ in diameter at a unidirectional sliding speed of $10 \mathrm{~cm} / \mathrm{s}$ for 5000 cycles was carried out using a CSM HT tribometer at different temperatures: room temperature, $300{ }^{\circ} \mathrm{C}$ and $600^{\circ} \mathrm{C}$. The wear tracks were sketched utilising a XP-Plus Stylus Profilometer and the wear area was calculated accordingly. The wear track was also observed under SEM and the composition of the wear debris and the scar were analysed by EDX.

\section{Results and discussion}

\subsection{Surface morphology and roughness}

After plasma co-alloying treatments, the surfaces were observed under SEM and the typical surface morphologies are shown in Fig. 1. After the plasma treatment, the surface morphology and roughness were changed mainly due to plasma sputtering and deposition, which were affected by both the gas composition and the alloying elements used. Figure 1a shows the typical surface morphology of the plasma nitrided (i.e. alloyed with $\mathrm{N}$ alone) CM247LC. It can be seen from Fig. 1a that a cauliflower feature was formed on the plasma nitrided surface. Large clusters (silver) are easily found on the active screen plasma co-alloyed surface with both $\mathrm{N}$ and V/Ag (Fig. 1b). The surface roughness was measured and the results are given in Table 2 .

\subsection{Surface hardness and phase identification}

After plasma nitriding (alloying with $\mathrm{N})$, the surface of CM247LC was much harder $\left(730 \mathrm{HV}_{0.025}\right)$ than that of untreated sample $\left(359 \mathrm{HV}_{0.025}\right)$. The $\mathrm{N} / \mathrm{V}$ co-alloyed surface was slightly softer than the PN 


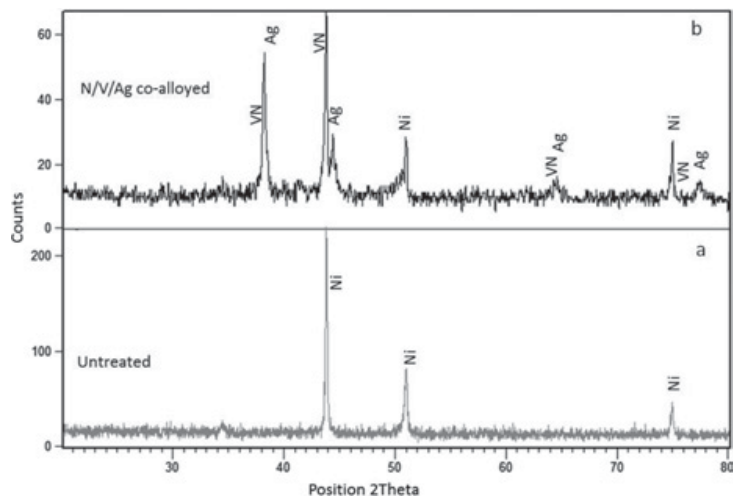

Figure 2. XRD charts for (a) untreated and (b) N/V/Ag co-alloyed surfaces.

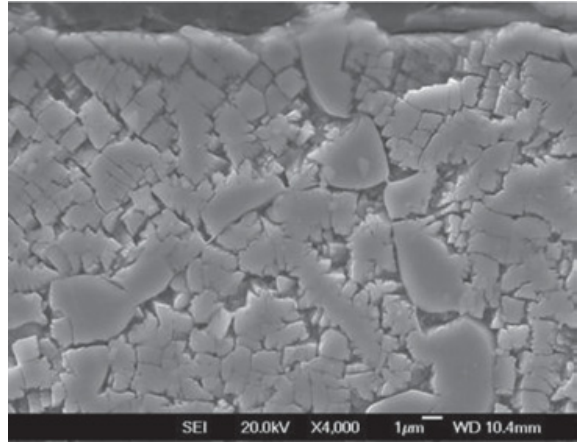

(a)

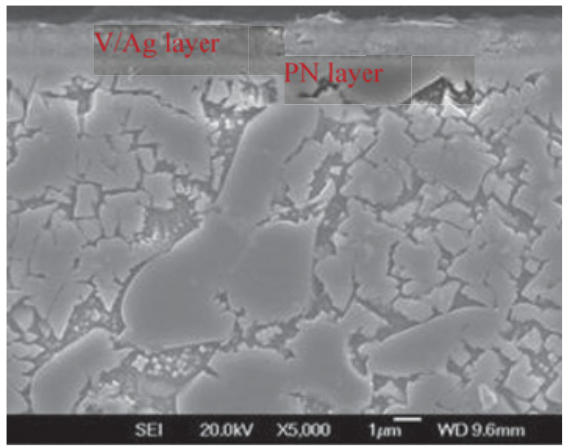

(b)

Figure 3. SEM cross sections of samples: (a) untreated and (b) ASP N/V/Ag co-alloyed CM247LC.

treated surface and the silver addition (i.e. N/V/Ag co-alloying) further reduced the surface hardness (Table 2).

XRD results revealed that VN was formed on the surface after active screen plasma co-alloying with $\mathrm{N}$ and $\mathrm{V}$ in a $25 \% \mathrm{~N}_{2} / 75 \% \mathrm{H}_{2}$ mixture at $450{ }^{\circ} \mathrm{C}$ for 25 hours. When co-alloyed under the same conditions but with $\mathrm{N}, \mathrm{V}$ and $\mathrm{Ag}$, the treated surface was dominated by Ag mainly due to the faster sputtering rate of $\mathrm{Ag}$ than $\mathrm{V}$ (Fig. 2).

\subsection{Surface layer structure}

Figure 3 shows typical cross sectional SEM pictures of untreated and ASP co-alloyed CM247LC alloy. Compared with the untreated sample (Fig. 3a), a thin (about $1 \mu \mathrm{m}$ thick) V/Ag co-alloyed layer was formed on the top of a shallow nitride case on CM247LC (Fig. 3b) after plasma co-alloying with nitrogen, vanadium and silver.

\subsection{Tribological behaviour}

During reciprocating friction test under a load of $2 \mathrm{~N}$ against a $\mathrm{Al}_{2} \mathrm{O}_{3}$ ball, the coefficient of friction $(\mathrm{CoF})$ of a $\mathrm{Al}_{2} \mathrm{O}_{3}$ ball against the untreated $\mathrm{CM} 247 \mathrm{LC}$ surface was gradually increased from 0.5 till 0.9 (Fig. 4). For the plasma nitrided surface, the CoF was initially high and gradually reduced to about 


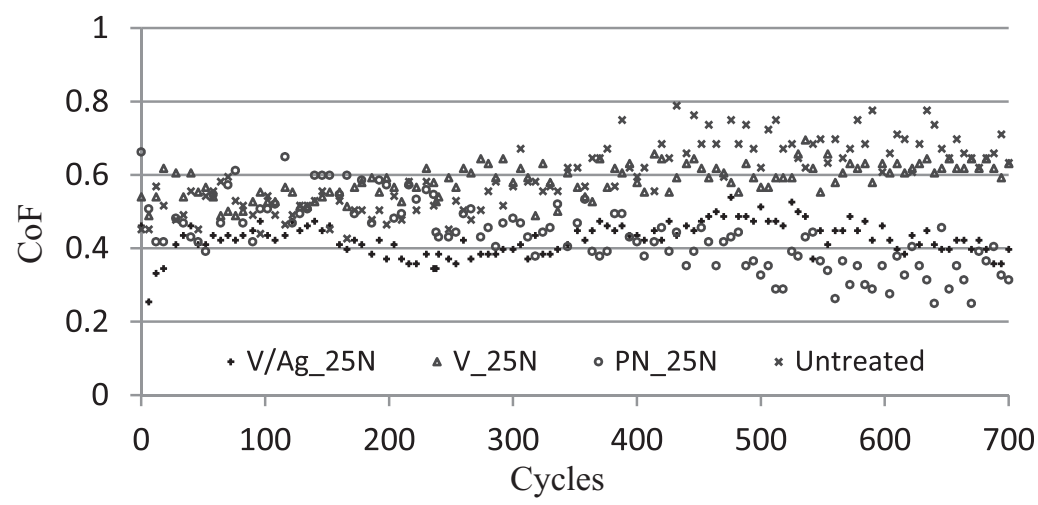

Figure 4. $\mathrm{CoF}$ of different surfaces against an $\mathrm{Al}_{2} \mathrm{O}_{3}$ ball under a load of $2 \mathrm{~N}$ at room temperature.

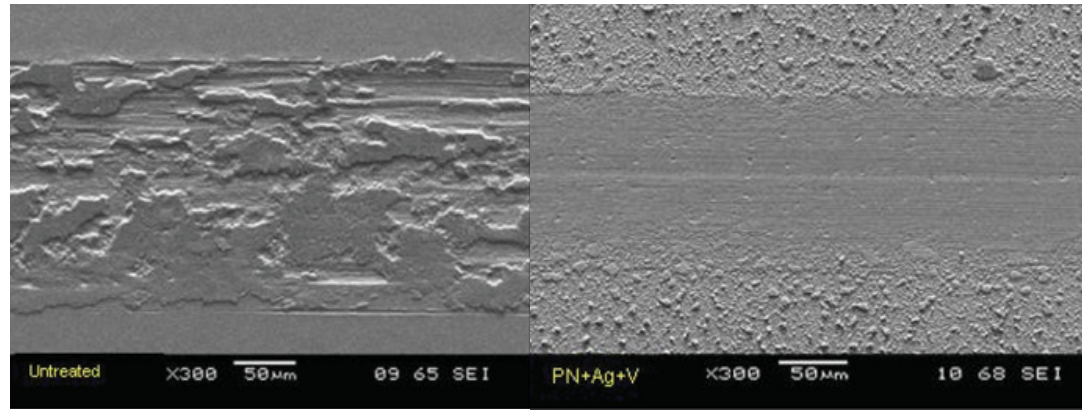

(a)

(b)

Figure 5. Wear tracks after 1000 cycles of test under $2 \mathrm{~N}$ at room temperature for (a) untreated (b) plasma N/V/Ag co-alloyed sample (V/Ag_25N).

0.4. The $\mathrm{CoF}$ for the $\mathrm{V} / \mathrm{N}$ co-alloyed surface followed the similar trend as for the untreated surface but the former showed a slightly lower $\mathrm{CoF}$ than the latter. As shown in Fig. 4, the CoF of the N/V/Ag co-alloyed surface is lower than that of N/V co-alloyed surfaces, suggesting that silver could reduce the coefficient of friction at room temperature. After 1000 cycles at room temperature, the wear was calculated and listed in Table 2. Post-test SEM observation revealed that the wear track formed in the untreated materials was wide and rough with many adhesive craters (Fig. 5a); in contrast, the wear track formed in the N/V/Ag co-alloyed surface looked smooth and the original rough superficial layer was removed suggesting mild abrasive wear (Fig. 5b).

The CoF curves of untreated and plasma alloyed surfaces at elevated temperatures were measured by a pin-on-disc wear tester. At room temperature, the $\mathrm{CoF}$ of the untreated sample fluctuated between 0.6 and 0.9, which is in agreement with the reciprocating tribo-test results (Fig. 4); it gradually decreased with the testing temperature $\left(\sim 0.6\right.$ at $300^{\circ} \mathrm{C}$ and 0.5 at $\left.600^{\circ} \mathrm{C}\right)$. For plasma nitrided surface, the $\mathrm{CoF}$ was only marginally lower than that of untreated surface at room temperature (RT) but clearly higher than that of other surfaces at elevated temperatures. This indicates that PN alone cannot effectively improve the tribological properties of CM247LC at elevated temperatures.

When tested at RT, the initial $\mathrm{CoF}$ of N/V/Ag co-alloyed surface was low $(<0.4)$ and it increased gradually to 0.6 at the end of the tribo-test (Fig. 6) because the surface layer was worn through (Fig. 7a). At $300^{\circ} \mathrm{C}$, the $\mathrm{CoF}$ of the N/V/Ag co-alloyed surface was consistently low $(<0.4)$ throughout the test (Fig. 6); however the $\mathrm{CoF}$ of other surfaces was all quite high especially for the N/V co-alloyed surface 


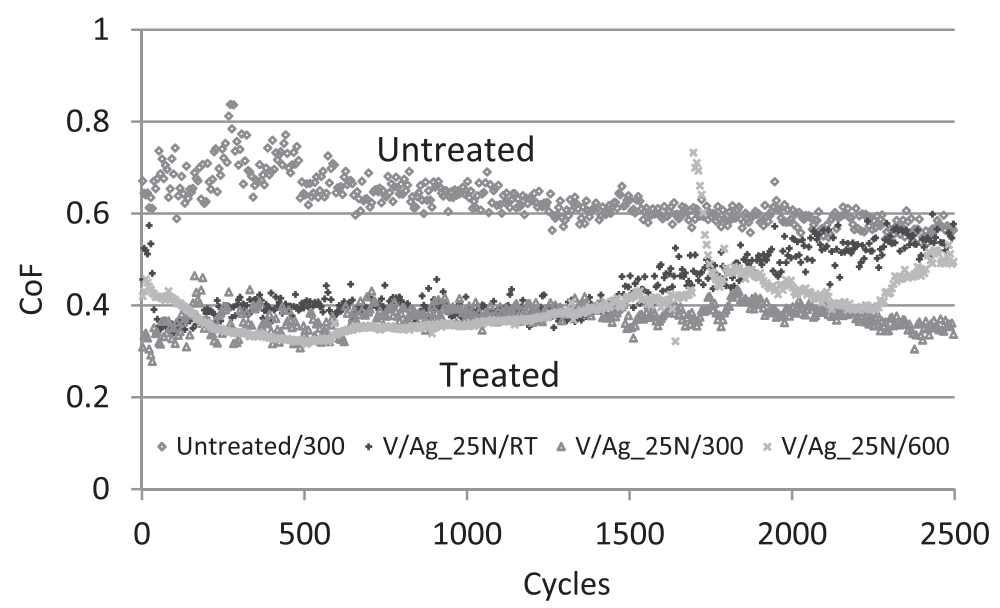

Figure 6. CoF curves of co-alloyed surface at room temperature, 300 and $600{ }^{\circ} \mathrm{C}$ with untreated $\left(300^{\circ} \mathrm{C}\right)$ in comparison.

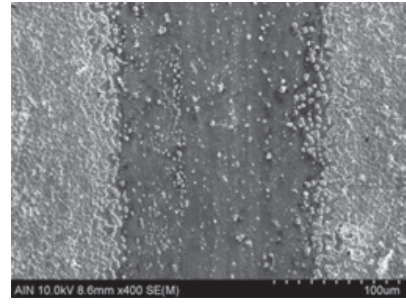

(a)

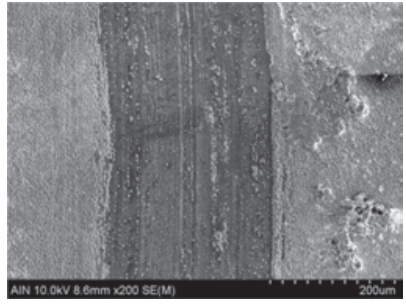

(b)

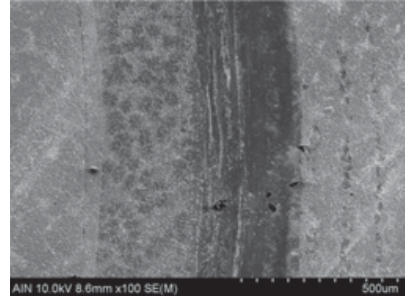

(c)

Figure 7. SEM images of wear tracks of N/V/Ag plasma co-alloyed surface after tribo-test at different temperatures: (a) room temperature, (b) $300{ }^{\circ} \mathrm{C}$ and (c) $600^{\circ} \mathrm{C}$.

(0.8). At $600^{\circ} \mathrm{C}$, the $\mathrm{CoF}$ of the N/V/Ag co-alloyed surface was even lower in the first half of the test, but it jumped and then fluctuated largely for the rest test period (Fig. 6). SEM observations on the track after $600^{\circ} \mathrm{C}$ tribo-test suggested that the surface layer was partially worn through as seen in Fig. 7(c). Elemental analysis by EDX on the surface indicated a high ratio of $\mathrm{Ag}: \mathrm{V}(7: 1)$ which resulted in a soft surface with low friction but high wear (Table 2). Some $\mathrm{V}_{2} \mathrm{O}_{5}$ oxides were also identified in the track. In short, the friction of the N/V/Ag co-alloyed surface was consistently better than other surfaces at elevated temperatures. The reduced friction can be attributed to the synergic lubrication effect of $\mathrm{Ag}$ and Magnéli oxide (i.e. $\mathrm{V}_{2} \mathrm{O}_{5}$ ) formed at elevated temperatures.

\section{Conclusions}

A novel active screen plasma (ASP) co-alloying technology has been developed to simultaneously alloy nickel based CM247LC superalloy surfaces with both interstitial element $\mathrm{N}$ (i.e. nitriding) and substitutional alloying elements (such as $\mathrm{V}$ and $\mathrm{Ag}$ ).

- After ASP co-alloying with N/V/Ag, a thin nano-composite layer consisting of Ag and VN can be formed on the top of a plasma nitrided shallow case in CM247LC sample. 
- All ASP treatments can effectively reduce the CoF of nickel superalloy from about 0.8 for the untreated materials to as low as 0.3-0.4 for the plasma treated surfaces when reciprocating against a ceramic ball at room temperature.

- When unidirectionally sliding against an $\mathrm{Al}_{2} \mathrm{O}_{3}$ ball at elevated temperatures up to $600^{\circ} \mathrm{C}$, the CoFs of the ASP N/V/Ag co-alloyed surface is consistently and significantly lower than those of the untreated and other ASP alloyed surfaces.

The research was funded by the EU FP7 Micro-FAST project (Contract No. GA608720).

\section{References}

[1] R. Orru, R. Licheri, A.M. Locci, A. Cincotti, G. Cao, Mater. Sci. Eng. R, 63, 127 (2009)

[2] H. Paschke, M. Weber, G. Braeuer etc., Arch. Civil. Mech. Eng., 12, 407 (2012)

[3] S. Grasso, Y. Sakka, G. Maizza, Sci. Technol. Adv. Mater. 10, 24 (2009)

[4] J.R. Davis, ASM Specialty Handbook: Tool Materials, ASM International, 236-239 (1995)

[5] Y. Saito and K. Mino, J. Tribology, 117, 524 (1995)

[6] Z. Zhang and H. Dong, Manufacturing Rev., 1, 24 (2015)

[7] W. Gulbiński W.T. Suszko, T.W. Sienicki, B. Warcholiński, Wear, 254, 129 (2003)

[8] S.M. Aouadi, D.P. Singh, D.S. Stone, K. Polychronopoulou, F. Nahif, C. Rebholz, Acta Mater. 58, $5326(2010)$ 